\title{
IMPLEMENTATION OF A FUZZY DECISION SUPPORT SYSTEM FOR SELECTION OF HAND TRACTOR ASSEMBLY SUPPLIERS
}

\author{
Denny Trias Utomo $\bowtie$ \\ Department of Information Technology \\ Politeknik Negeri Jember \\ 164 Jl. Mastrip, Jember, Indonesia, 68100 \\ denny_trias@polije.ac.id \\ Pratikto \\ Department of Mechanical Engineering ${ }^{1}$ \\ Purnomo Budi Santoso \\ Departement of Industrial Engineering ${ }^{1}$ \\ Sugiono \\ Departement of Industrial Engineering ${ }^{1}$ \\ ${ }^{1}$ Brawijaya University \\ Jl. Veteran, Ketawanggede, Kota Malang, Indonesia, 65145
}

$\triangle$ Corresponding author

Abstract

Supplier selection is a complex problem in the current Industry 4.0 era. The large number of suppliers with different performance qualities makes it difficult for the company's internal parties to choose the appropriate supplier. The suitability of quality suppliers needed to supply raw materials needed by the industry is an important matter to be resolved. In the hand tractor assembly industry, this small and medium industry is also very dependent on the availability of supply materials, and of course it also depends on the selection of the supplier itself. In this study, the object of research is the 151 hand tractor assembly manufacturing industry using 10 main criteria for selecting suppliers. Each criterion has a weight that is calculated using the Fuzzy AHP method so as to obtain alternative supplier results that are displayed in order.

A supplier is a company or individual that provides the raw materials needed by the company and its competitors to produce certain goods. In this study, a decision support system for supplier selection at the company has been developed using the AHP fuzzy method. The results of this study are expected to help companies in selecting suppliers that match the predetermined criteria. In building a decision support system that provides supplier recommendations, the authors apply the AHP fuzzy method in the process. With the Supplier Selection Decision Support System Using the AHP Fuzzy Method, it can help companies in selecting suppliers. Based on the research that has been done, suggestions can be made for a Decision Support System for Supplier Selection Using the Fuzzy AHP Method so that in the future it can facilitate the use of a more dynamic system.

Keywords: supplier, decision support system, fuzzy analytic hierarchy process, hand-tractor manufacturing.

DOI: $10.21303 / 2461-4262.2022 .001864$

\section{Introduction}

In an era with certain artificial intelligence technologies that are embedded in applications in the form of an intelligent knowledge base so that they can make decisions without human involvement [1], it can detect an area autonomously and can detect a small movement that cannot be detected by the human eye [1,2], of this is the advancement of artificial intelligence technology in helping humans, while the implementation in the world of free trade today, companies as much as possible manage their production as well as possible. One of the things that need to be considered in managing production, companies must be able to reduce existing costs in order to provide low prices with good quality to consumers, so that they are ready to compete globally. There are various kinds of costs, one of which is the cost from the supplier [3]. 
Suppliers are business partners who play an important role in providing the raw materials needed by the company. In general, all suppliers are almost the same, but the characteristics of each supplier are different. The large selection of suppliers with different characteristics requires companies to be extra careful in choosing suppliers [4].

Selection of suppliers of raw materials by company criteria is needed, because the wrong supplier selection can affect the company's operations [5]. Choosing a supplier that fits the criteria will provide benefits for the company. The selections of suppliers who have not collaborated are not easy, because data is not yet available and supplier performance is not known. One of the criteria for becoming a supplier is having the ability to manage the inventory of goods to be sent to the company. In selecting a new supplier wishing to join the company determining suitable criteria can consume a lot of time, cost, and effort. Another case with old suppliers, who have worked with the company, because the company already has historical data on the supplier's performance [6].

With the development of technology, selecting a supplier with a computer system is needed. Thus, a supplier selection decision support system can be developed using the Fuzzy Analytical Hierarchy Process (F-AHP) method which is expected to assist companies in selecting suitable new suppliers and can improve performance in existing decision making. Fuzzy AHP is an implementation of the Fuzzy Multiple Attribute Decision Making (FMADM) [7] algorithm and Analytical Hierarchy Process [8].

\section{Materials and methods}

A supplier is a company or individual that provides raw materials needed by companies and competitors to produce certain goods [9]. In selecting suppliers, various criteria are needed that can describe the overall performance of the supplier. There need to be supplier criteria set by the company to provide feedback for both parties. It is necessary to weight the criteria that have been determined in selecting the appropriate supplier [10].

The main objective of the supplier selection process is to determine a supplier that is efficient in meeting company needs consistently and minimizes risks related to the procurement of raw materials. There are general technical criteria in selecting suppliers of raw materials in the manufacturing industry, as stated by experts consisting of 10 general factors, [11] namely:

1. Management Capability: relates to quality systems, information management, and total quality management.

2. Price: the price offered must be competitive and provide a discount.

3. Environmental Awareness: suppliers must be aware that the customer (industrial company) has a responsibility to the environment, namely disclosing confidential materials, disposing of packaging from customers, and disposing of obsolete and or failed products.

4. Delivery Performance: products are delivered at the right time and in the right quantity.

5. Service or service: service suppliers must follow the complaint handling instructions, ease of doing business, and respond quickly.

6. Flexibility: the ability to adjust the volume and time of delivery.

7. Technical Ability: modern equipment, the ability to keep up with developments.

8. Innovative: innovations are made in order to improve products and reduce costs.

9. Management Approach: good relationship and commitment to company management.

10. Geographical Position: the location or location of the supplier.

F-AHP is a combination of the AHP method with the fuzzy concept approach. F-AHP covers the weaknesses found in AHP, namely the problem of criteria that have more subjective characteristics. The uncertainty of numbers is represented by an order of scale. The steps for solving the Fuzzy Analytical Hierarchy Process (F-AHP) [12]:

1) Determine the value of priority fuzzy synthesis $S i$ with the formula:

$$
S i=\sum_{j=1}^{m} M_{g i}^{j} \mathrm{X} \frac{1}{\left[\sum_{i=1}^{n} \sum_{j=1}^{m} M_{g i}^{j}\right]},
$$

where $S i$ - grades synthesis $f u z z y ; M$ - number of criteria; $i$ - row; $j$ - columns; $g$ - parameter $(l, m, u)$. 
To get $\sum_{j=1}^{m} M_{g i}^{j}$, namely by using the addition fuzzy of the values $m$ in a matrix as in the (2):

$$
\sum_{j=1}^{m} M_{g i}^{j}=\left(\sum_{j=1}^{m} l_{j}, \sum_{j=1}^{m} m_{j}, \sum_{j=1}^{m} u_{j}\right)
$$

Whereas to get, $1 /\left[\sum_{i=1}^{n} \sum_{j=1}^{m} M_{g i}^{j}\right]$ the addition operation performed fuzzy from $M i s_{g i}^{j}(j=1,2, \ldots, m)$ in the decision matrix $(n \times m)$ as follows:

$$
\frac{1}{\sum_{j=1}^{n} \sum_{j=1}^{m} M_{i j}}=\frac{1}{\sum_{j=1}^{n} u_{i} \cdot \sum_{i=1}^{n} m_{i} \cdot \sum_{i=1}^{n} l_{i}} .
$$

2) Determine the Vector Value $(V)$ and the Ordinate Value $\left(d^{\prime}\right)$.

If the results obtained for each matrix fuzzy $M_{2}=\left(l_{2}, m_{2}, u_{2}\right) \geq M_{1}=\left(l_{1}, m_{1}, u_{1}\right)$ can be defined as a vector value:

$$
\begin{aligned}
& V\left(M_{2} \geq M_{1}\right)=\sup \left[\min \left(\mathrm{j} M_{1}(x)\right), \min \left(\mathrm{j} M_{2}(y)\right)\right], \\
& V\left(M_{2} \geq M_{1}\right)=\left\{\begin{array}{ll}
1, & \text { if } m_{2} \geq m_{1}, \\
0, & \text { if } l_{1} \geq u_{2}, \\
\frac{l_{1}-u_{2}}{\left(m_{2}-u_{2}\right)-\left(m_{1}-l_{1}\right)}, & \text { others }
\end{array}\right\} .
\end{aligned}
$$

If the resulting fuzzy value is greater than $k, M_{i}(i=1,2, . ., k)$ then the vector value can be defined as follows:

$$
V\left(M \geq M_{1}, M_{2}, \ldots M_{k}\right)=V\left(M \geq M_{1}\right) \text { and } V\left(M \geq M_{2}\right) \text { and } V\left(M \geq M_{k}\right)=\min V\left(M \geq M_{i}\right),
$$

with $V$-value vector; $M$ - Matrix grades synthesis fuzzy; $i-1,2,3, \ldots k$.

Thus obtained value of the ordinate $\left(d^{\prime}\right)$ :

$$
d^{\prime}\left(A_{i}\right)=\min V\left(S_{i} \geq S_{k}\right)
$$

where $S_{i}$ - synthesis value fuzzy of the $S_{k}$ - synthesis value the other fuzzy for $k=1,2, \ldots n ; k \neq i$, then let's obtain the vector weight value:

$$
W^{\prime}=\left(d^{\prime}\left(A_{1}\right), d^{\prime}\left(A_{2}\right), \ldots d^{\prime}\left(A_{n}\right)\right)^{T},
$$

with $A_{i}(i=1,2, \ldots, n)$ is $n$ decision elements and $d^{\prime}\left(A_{i}\right)$ is a value that describes the relative choice of each decision attribute.

3) Normalization of fuzzy vector weight values $(W)$.

Normalization of weight values the vector is obtained by the equation:

$$
\begin{gathered}
d\left(A_{n}\right)=\frac{d^{\prime}\left(A_{n}\right)}{\sum_{j=1}^{n} d^{\prime}\left(A_{n}\right)}, \\
W=\left(d\left(A_{1}\right), d\left(A_{2}\right), \ldots d\left(A_{n}\right)\right)^{T},
\end{gathered}
$$

where $W$ is a non-fuzzy number. 


\section{Results and discussion}

In this paper, the first step taken to select the best supplier using the F-AHP method is to compile a hierarchical structure of the problems at hand. In compiling a hierarchy begins with determining the goals of the problems faced, then determining the criteria and alternatives. The objective of the problem in this research is to choose the best supplier. There are 10 criteria used in this study to select the best supplier, namely Management Capability (K1), Price (K2), Environmental Awareness (K3), Delivery (K4), Service (K5), Flexibility (K6), Technical Capability (K7), Innovative (K8), Management Approach (K9) and Geographical Position (K10). Calculation of the Criteria Priority Weights:

1. Making a paired comparison matrix of criteria.

At this stage, an assessment of the comparison between one criterion and another is conducted. The criteria pairwise comparison matrix can be seen in the following Table 1. The total value in Table 2 is obtained by adding up the comparison values in each column.

Table 1

Matrix Pairwise Comparison

\begin{tabular}{ccccccccccc}
\hline- & K1 & K2 & K3 & K4 & K5 & K6 & K7 & K8 & K9 & K10 \\
\hline K1 & 1.00 & 0.20 & 3.00 & 0.33 & 0.33 & 0.33 & 1.00 & 1.00 & 3.00 & 0.33 \\
K2 & 5.00 & 1.00 & 7.00 & 3.00 & 3.00 & 3.00 & 5.00 & 3.00 & 5.00 & 3.00 \\
K3 & 0.33 & 0.14 & 1.00 & 0.20 & 0.20 & 0.20 & 0.33 & 0.20 & 0.33 & 0.33 \\
K4 & 3.00 & 0.33 & 5.00 & 1.00 & 3.00 & 3.00 & 3.00 & 3.00 & 3.00 & 3.00 \\
K5 & 3.00 & 0.33 & 5.00 & 0.33 & 1.00 & 1.00 & 3.00 & 3.00 & 3.00 & 3.00 \\
K6 & 3.00 & 0.33 & 5.00 & 0.33 & 1.00 & 1.00 & 3.00 & 3.00 & 3.00 & 3.00 \\
K7 & 1.00 & 0.20 & 3.00 & 0.33 & 0.33 & 0.33 & 1.00 & 0.33 & 3.00 & 0.33 \\
K8 & 1.00 & 0.33 & 5.00 & 0.33 & 0.33 & 0.33 & 3.00 & 1.00 & 3.00 & 3.00 \\
K9 & 0.33 & 0.20 & 3.00 & 0.33 & 0.33 & 0.33 & 0.33 & 0.33 & 1.00 & 0.33 \\
K10 & 3.00 & 0.33 & 3.00 & 0.33 & 0.33 & 0.33 & 3.00 & 0.33 & 3.00 & 1.00 \\
Sum & 20.67 & 3.41 & 40.00 & 6.53 & 9.87 & 9.87 & 22.67 & 15.20 & 27.33 & 17.33
\end{tabular}

Table 2

Calculation Consistency Ratio

\begin{tabular}{|c|c|c|}
\hline Vector Priority & Priority & Lambda \\
\hline 0.580 & 0.054 & 10.741 \\
\hline 2.854 & 0.255 & 11.187 \\
\hline 0.231 & 0.021 & 10.832 \\
\hline 2.014 & 0.174 & 11.564 \\
\hline 1.404 & 0.123 & 11.377 \\
\hline 1.404 & 0.123 & 11.377 \\
\hline 0.521 & 0.050 & 10.521 \\
\hline 0.958 & 0.087 & 10.997 \\
\hline 0.380 & 0.036 & 10.539 \\
\hline 0.813 & 0.076 & 10.723 \\
\hline \multicolumn{2}{|c|}{ Lambda max } & 10.986 \\
\hline \multicolumn{2}{|c|}{ CI } & 0.110 \\
\hline \multicolumn{2}{|c|}{$\mathrm{CR}$} & 0.074 \\
\hline
\end{tabular}

2. Determination of priority value criteria.

To determine priority value criteria namely by dividing the value of each cell by the number of each column. After obtaining the results of the distribution of each column, the priority value of the criteria can be calculated. The criteria priority value is calculated by dividing the total value in each row by the number of criteria. 
3. Consistency Measurement.

In measuring consistency, the lambda max, CI, and $\mathrm{CR}$ are calculated. If the $\mathrm{CR}$ value is $\leq 0.1$, the pairwise comparison matrix is declared consistent. The priority vector value is obtained from the multiplication of the pairwise comparison matrix with the priority value, while the priority value is obtained from the previous calculation. The lambda value is obtained from the division of the priority vector value by the priority value. Calculating the lambda max value is obtained from the total lambda divided by the number of criteria and calculating the CI and CR values, can be seen at Table 2, and the value of sythesis fuzzy can be seen at Table $\mathbf{3}$.

Table 3

Value Synthesis Fuzzy

\begin{tabular}{ccccccc}
\hline- & \multicolumn{3}{c}{ Number of Rows } & \multicolumn{1}{c}{$\boldsymbol{S i}$} \\
\hline K1 & $\boldsymbol{l}$ & $\boldsymbol{m}$ & $\boldsymbol{u}$ & $\boldsymbol{l}$ & $\boldsymbol{m}$ & 0.133 \\
K2 & 7.333 & 9.067 & 11.500 & 0.050 & 0.080 & 0.277 \\
K3 & 15.000 & 19.500 & 24.000 & 0.102 & 0.171 & 0.085 \\
K4 & 4.583 & 5.552 & 7.333 & 0.031 & 0.049 & 0.219 \\
K5 & 10.500 & 14.667 & 19.000 & 0.072 & 0.129 & 0.196 \\
K6 & 10.000 & 13.333 & 17.000 & 0.068 & 0.117 & 0.196 \\
K7 & 10.000 & 13.333 & 17.000 & 0.068 & 0.117 & 0.133 \\
K8 & 6.833 & 8.733 & 11.500 & 0.047 & 0.077 & 0.173 \\
K9 & 9.000 & 11.667 & 15.000 & 0.061 & 0.103 & 0.121 \\
K10 & 5.833 & 7.567 & 10.500 & 0.040 & 0.067 & 0.162 \\
Total & 7.500 & 10.333 & 14.000 & 0.051 & 0.091 &
\end{tabular}

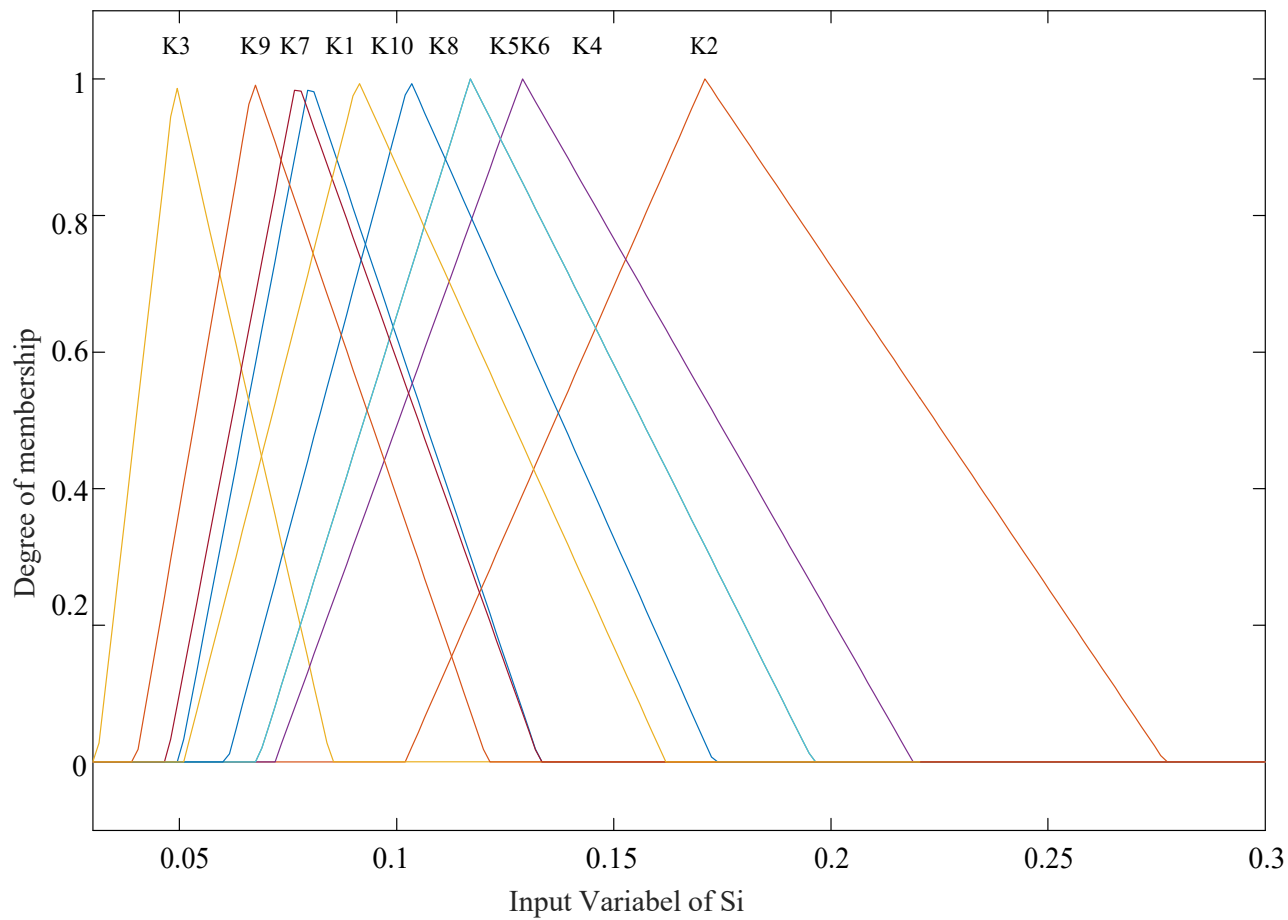

Fig. 1. Membership Function of $S i$

Change the value matrix of pairwise comparison criteria to the F-AHP.

Conversion AHP pairwise comparison values to set values fuzzy (F-AHP) were performed using TFN.

Determining the value of synthesis fuzzy $S i$ priorities. 
Based on Table 4 the number of lines $l, m, u$ is obtained from the sum of the value of $l, m, u$ in each row. The value of the synthesis fuzzy row $K 1$ column $l$ is obtained from the quotient between the number of rows $l$ criteria 1 with the total value of $u$ in the number of rows. The value of the synthesis fuzzy row $K 1$ column $m$ is obtained from the quotient between the number of rows $m$ criterion 1 with the total value $m$ in the number of rows, while the value of fuzzy is row $K 1$ column obtained from the quotient between the number of rows $u$ criteria 1 with the total value $l$ in the number of rows.

4. Calculation of the F-AHP vector value $(V)$ and the defuzzification ordinate value $\left(d^{\prime}\right)$. The process of calculating the F-AHP vector value and ordinate value is defuzzification carried out by (4)-(6).

From the calculation Table 4, it can be calculated the values of $v$ and $d^{\prime}$ :

$V_{s} K 1 \geq\left(V_{s} K 2, V_{s} K 3, V_{s} K 4, V_{s} K 5, V_{s} K 6, V_{s} K 7, V_{s} K 8, V_{s} K 9, V_{s} K 10\right)$,

$$
\begin{gathered}
V_{s} K 1 \geq V_{s} K 2=1, \\
V_{s} K 1 \geq V_{s} K 3=\frac{0.50-0.85}{(0.049-0.085)-(0.079-0.050}=0.529, \\
V_{s} K 1 \geq V_{s} K 4=1, \\
V_{s} K 1 \geq V_{s} K 5=1, \\
V_{s} K 1 \geq V_{s} K 6=1, \\
0.080-0.133 \\
V_{s} K 1 \geq V_{s} K 7=\frac{0.133)-(0.079-0.049}{(0.077-0.966,} \\
V_{s} K 1 \geq V_{s} K 8=1, \\
0.050-0.162 \\
V_{s} K 1 \geq V_{s} K 9=\frac{V_{s} K 10=1 .}{(0.091-0.162)-(0.080-0.050=0.844}=0.844,
\end{gathered}
$$

So that the ordinate value fuzzy $\left(d^{\prime}\right)$ :

$$
\left(d^{\prime}\left(V_{s} K 1\right)=\min (1 ; 0.529 ; 1 ; 1 ; 1 ; 0.966 ; 1 ; 0.844 ; 1) .\right.
$$

Based on the ordinate values $K 1, K 2, K 3, K 4, K 5, K 6, K 7, K 8, K 9$ and $K 10$, the vector weight values fuzzy can be determined using equation (8) as follows:

$$
W^{\prime}=(0.529 ; 0 ; 1 ; 0.141 ; 0.195 ; 0.195 ; 0.577 ; 0.303 ; 0.717 ; 0.444)^{T}, \Sigma W^{\prime}=4.103 .
$$

5. Normalization of fuzzy vector weight values $(W)$.

Normalization of vector weight values is fuzzy obtained by the equation (10), where each element is weighted the vector is divided by the weight of the vector itself, so that the weight of the (local) criteria obtained is $0.129 ; 0 ; 0.244 ; 0.034 ; 0.048 ; 0.048 ; 0.141 ; 0.074 ; 0.175 ; 0.108$.

Solution steps are the same as the completion step for the criteria. Each supplier is assessed on basic criteria. The value assigned to the supplier is used to compare the value of the supplier against the criteria being assessed, namely $K 1, \ldots, K 10$. The value of suppliers can be seen in Table 4. 
Table 4

Sample Value of Suppliers

\begin{tabular}{ccccccccccc}
\hline Alternative & K1 & K2 & K3 & K4 & K5 & K6 & K7 & K8 & K9 & K10 \\
\hline Alternative 1 & 5 & 4 & 3 & 5 & 5 & 4 & 5 & 4 & 4 & 2 \\
Alternative 2 & 4 & 5 & 4 & 2 & 3 & 3 & 4 & 3 & 4 & 5 \\
Alternative 3 & 5 & 5 & 4 & 4 & 4 & 3 & 3 & 4 & 4 & 4
\end{tabular}

Steps - the alternative completion step is the same as the completion step on the criterion.

The supplier values against the criteria will be compared one by one into the AHP and F-AHP comparison matrix. Each supplier is initialized as an alternative $A$. The following is AHP's pairwise comparison matrix can be seen in Table $\mathbf{5}$.

Table 5

Pairwise Comparison Matrix

\begin{tabular}{cccc}
\hline Alternative & $\boldsymbol{A 1}$ & $\boldsymbol{A 2}$ & $\boldsymbol{A 3}$ \\
\hline$A 1$ & 1 & 2 & 1.000 \\
$A 2$ & 0.500 & 1 & 0.500 \\
$A 3$ & 1.000 & 2.000 & 1 \\
Total & 2.500 & 5.000 & 2.500
\end{tabular}

6. Changing the alternative pairwise comparison matrix value to F-AHP.

From Tabel 5, the pairwise comparison matrix values are converted into set values fuzzy (F-AHP). The alternative F-AHP pairwise comparison matrix can be seen in Table 6.

Table 6

Matrix Comparison TFN

\begin{tabular}{ccccccccccc}
\hline \multirow{2}{*}{ TFN } & $\boldsymbol{A 1}$ & \multicolumn{1}{c}{$\boldsymbol{A 2}$} & \multicolumn{3}{c}{$\boldsymbol{A 3}$} \\
\cline { 2 - 10 } & $\boldsymbol{l}$ & $\boldsymbol{m}$ & $\boldsymbol{u}$ & $\boldsymbol{l}$ & $\boldsymbol{m}$ & $\boldsymbol{u}$ & $\boldsymbol{l}$ & $\boldsymbol{m}$ & $\boldsymbol{u}$ \\
\hline$A 1$ & 1 & 1 & 1 & $2 / 3$ & 1 & 2 & $2 / 3$ & 1 & 2 \\
$A 3$ & $1 / 2$ & 1 & $11 / 2$ & 1 & 1 & 1 & 1 & 1 & 1 \\
& $1 / 2$ & 1 & $11 / 2$ & 1 & 1 & 1 & 1 & 1
\end{tabular}

Determining the value off fuzzy synthesis $S i$ priority value of synthesis is fuzzily obtained from data processing in Table 6, so that the synthesis value obtained $(\mathrm{Si})$ is in Table 7.

Table 7

Value Synthesis Fuzzy

\begin{tabular}{ccccccc}
\hline \multirow{2}{*}{ Alternative } & \multicolumn{3}{c}{ Number of Rows } & \multicolumn{3}{c}{$\boldsymbol{S}$} \\
\cline { 2 - 7 } & $\boldsymbol{l}$ & $\boldsymbol{m}$ & $\boldsymbol{u}$ & $\boldsymbol{l}$ & $\boldsymbol{m}$ & $\boldsymbol{u}$ \\
\hline$A 1$ & 2.333 & 3.000 & 5.000 & 0.194 & 0.333 & 0.682 \\
$A 2$ & 2.500 & 3.000 & 3.500 & 0.208 & 0.333 & 0.477 \\
$A 3$ & 2.500 & 3.000 & 3.500 & 0.208 & 0.333 & 0.477 \\
Total & 7.333 & 9.000 & 12.000 & - & - & -
\end{tabular}

7. The calculation of the value of the vector F-AHP $(V)$ and the ordinate defuzzification $\left(d^{\prime}\right)$ :

a) $V_{s} A 1 \geq\left(V_{s} A 2, V_{s} A 3\right), V_{s} A 1 \geq V_{s} A 2=1, V_{s} A 1 \geq V_{s} A 3=1$, value fuzzy $\left(d^{\prime}\right)$ :

$$
\left(d^{\prime} V_{s} A 1\right)=\min (1 ; 1) \text {. }
$$


b) $V_{s} A 2 \geq\left(V_{s} A 1, V_{s} A 3\right), V_{s} A 2 \geq V_{s} A 1=1, V_{s} A 2 \geq V_{s} A 3=1$, value fuzzy $\left(d^{\prime}\right)$ :

$$
d^{\prime}\left(V_{s} K 2\right)=\min (1 ; 1)
$$

c) $V_{s} A 3 \geq\left(V_{s} A 1, V_{s} A 2\right), V_{s} A 3 \geq V_{s} A 1=1, V_{s} A 3 \geq V_{s} A 2=1$, value fuzzy $\left(d^{\prime}\right)$ :

$$
d^{\prime}\left(V_{s} A 3\right)=\min (1 ; 1)
$$

From the ordinate values $A 1, A 2$ and $A 3$, the vector weight values can be determined fuzzy as follows:

$$
W^{\prime}=(1 ; 1 ; 1)^{T}, \Sigma W^{\prime}=3
$$

8. Normalization of the fuzzy vector weight value $(W)$.

From the alternative calculation of the above criteria, the priority weight of each alternative (supplier) is obtained, namely the weight $A 1=0.333$, the weight $A 2=0.333$ and the weight of $A 3=0.333$.

9. Alternative ranking and decision results.

The alternative ranking is a step to get the final decision. At this stage, the global weight value is calculated by multiplying the weight $(W)$ of the priority of each alternative by the weight of the criteria's local priority and adding the multiplication results of each alternative. The sum of weights produces global weights which are then ranked and obtained by the best suppliers. The following is Table 8 of the final results of determining the best supplier.

Table 8

Alternative Rank

\begin{tabular}{ccccccccccccc}
\hline $\begin{array}{c}\text { Global } \\
\text { Weight }(\boldsymbol{W})\end{array}$ & $\mathbf{0 . 1 2 9}$ & $\mathbf{0 . 0 0 0}$ & $\mathbf{0 . 2 4 4}$ & $\mathbf{0 . 0 3 4}$ & $\mathbf{0 . 0 4 8}$ & $\mathbf{0 . 0 4 8}$ & $\mathbf{0 . 1 4 1}$ & $\mathbf{0 . 0 7 4}$ & $\mathbf{0 . 1 7 5}$ & $\begin{array}{c}\text { K10 } \\
\mathbf{0 . 1 0 8}\end{array}$ & Weight & Rank \\
\hline$A 1$ & 0.333 & 0.333 & 0.333 & 0.200 & 0.297 & 0.333 & 0.297 & 0.333 & 0.333 & 0.531 & 0.343 & 1 \\
$A 2$ & 0.333 & 0.333 & 0.333 & 0.531 & 0.366 & 0.333 & 0.337 & 0.333 & 0.333 & 0.200 & 0.328 & 3 \\
$A 3$ & 0.333 & 0.333 & 0.333 & 0.268 & 0.337 & 0.333 & 0.366 & 0.333 & 0.333 & 0.268 & 0.329 & 2
\end{tabular}

Based on calculations using fuzzy AHP gained global significance of each alternative (suppliers), i.e. $A 1=0.343 ; A 2=0.328$ and $A 3=0.329$. The global weight of each alternative is used to determine the ranking of the best alternative, where the alternative with the highest global weight will get the best ranking.

In this study, all parameters were calculated manually using the Fuzzy AHP method, which allowed for numerical calculation errors. Suggestions for the next researcher, the Fuzzy AHP algorithm should be used as a software application so that this calculation is carried out automatically, thereby reducing errors.

\section{Conclusions}

Based on the descriptions and discussions that have been stated, it can be concluded that in building a decision support system that provides supplier recommendations, the authors apply the method fuzzy AHP in the process. The application of the method fuzzy AHP to the system and manual calculations give the same ranking results. With the Supplier Selection Decision Support System Using the Method Fuzzy AHP, it can help companies in selecting at least 151 suppliers.

Based on the research that has been done, suggestions for a Supplier Selection Decision Support System Using the Method Fuzzy AHP in the future can make it easier to use the system is made more dynamic so that the criteria for selecting suppliers can be added, edited, and deleted. 


\section{Acknowledgment}

The author would like to thank the Department of Information Technology Politeknik Negeri Jember and Faculty of Engineering Universitas Brawijaya Malang (Indonesia) for the support of this research.

\section{References}

[1] Utomo, D. T., Pratikto, Santoso, P. B., Sugiono. (2020). Preliminary Study of Web Based Decision Support System to Select Manufacturing Industry Suppliers. Journal of Southwest Jiaotong University, 55 (2). doi: https://oi.org/10.35741/ issn.0258-2724.55.2.27

[2] An, M., Chen, Y., Baker, C. J. (2011). A fuzzy reasoning and fuzzy-analytical hierarchy process based approach to the process of railway risk information: A railway risk management system. Information Sciences, 181 (18), $3946-3966$. doi: https://doi.org/10.1016/j.ins.2011.04.051

[3] Ordoobadi, S. M. (2009). Development of a supplier selection model using fuzzy logic. Supply Chain Management: An International Journal, 14 (4), 314-327. doi: https://doi.org/10.1108/13598540910970144

[4] Sutrisno, Wicaksono, P. A. (2015). Optimal Strategy for Multi-product Inventory System with Supplier Selection by Using Model Predictive Control. Procedia Manufacturing, 4, 208-215. doi: https://doi.org/10.1016/j.promfg.2015.11.033

[5] Sinha, A. K., Anand, A. (2018). Development of sustainable supplier selection index for new product development using multi criteria decision making. Journal of Cleaner Production, 197, 1587-1596. doi: https://doi.org/10.1016/j.jclepro.2018.06.234

[6] Sarkar, S., Pratihar, D. K., Sarkar, B. (2018). An integrated fuzzy multiple criteria supplier selection approach and its application in a welding company. Journal of Manufacturing Systems, 46, 163-178. doi: https://doi.org/10.1016/j.jmsy.2017.12.004

[7] Kumar, S., Kumar, S., Barman, A. G. (2018). Supplier selection using fuzzy TOPSIS multi criteria model for a small scale steel manufacturing unit. Procedia Computer Science, 133, 905-912. doi: https://doi.org/10.1016/j.procs.2018.07.097

[8] Azimifard, A., Moosavirad, S. H., Ariafar, S. (2018). Selecting sustainable supplier countries for Iran's steel industry at three levels by using AHP and TOPSIS methods. Resources Policy, 57, 30-44. doi: https://doi.org/10.1016/j.resourpol.2018.01.002

[9] Croxton, K. L., García-Dastugue, S. J., Lambert, D. M., Rogers, D. S. (2001). The Supply Chain Management Processes. The International Journal of Logistics Management, 12 (2), 13-36. doi: https://doi.org/10.1108/09574090110806271

[10] Dalalah, D., Hayajneh, M., Batieha, F. (2011). A fuzzy multi-criteria decision making model for supplier selection. Expert Systems with Applications, 38 (7), 8384-8391. doi: https://doi.org/10.1016/j.eswa.2011.01.031

[11] Kusiak, A. (2000). Computational Intelligence in Design and Manufacturing. Wiley, 560.

[12] Zhang, J. J. (2000). Fuzzy analytical hierarchy process. Fuzzy systems and mathematics, 14 (2), 80-88.

Received date 07.06.2021

Accepted date 10.12.2021

Published date 10.01.2022
(C) The Author(s) 2021

This is an open access article under the Creative Commons CC BY license

How to cite: Utomo, D. T., Pratikto, P., Santoso, P. B., Sugiono, S. (2022). Implementation of a fuzzy decision support system for selection of hand tractor assembly suppliers. EUREKA: Physics and Engineering, 1, 44-52. doi: https://doi.org/10.21303/ 2461-4262.2022.001864 